Article

\title{
An Exploration of Relationships among Thermal Insulation, Area Factor and Air Gap of Male Chinese Ethnic Costumes
}

\author{
Ying $\mathrm{Ke}^{1}$ and Faming Wang ${ }^{2, *(1)}$ \\ 1 Jiangsu Non-material Culture Heritage Research Base, Jiangnan University, Wuxi 214122, China; \\ keying@jiangnan.edu.cn \\ 2 School of Architecture and Art, Central South University, Changsha 410083, China \\ * Correspondence: dr.famingwang@gmail.com; Tel.: +86-137-9946-9070
}

Received: 13 May 2020; Accepted: 5 June 2020; Published: 6 June 2020

\begin{abstract}
The present study investigated total and local thermal insulations of 39 sets of male Chinese ethnic costumes. Total and local clothing area factor, air gap size and air volume were determined by a 3D body scanner. Relationships between thermal insulation and air gap for the whole body, as well as local body parts, were explored. Correlations of both the total and local clothing area factor with the intrinsic insulation were also developed. Results demonstrated that the clothing total thermal insulation first increased with the increasing air gap size/air volume, followed by a decrease when the air gap size/air volume exceeded $37.8 \mathrm{~mm} / 55.8 \mathrm{dm}^{3}$. Similarly, it was also found that parabolic relationships widely existed between the local thermal insulation and local air gap at each body part. Our research findings provide a comprehensive database for predicting both global and local thermal comfort of male Chinese minority groups.
\end{abstract}

Keywords: local thermal insulation; air gap; clothing area factor; ethnic costume; 3D body scanner

\section{Introduction}

Thermal insulation plays an important role in determining clothing's thermal comfort and human thermal stress [1,2]. Existing studies have demonstrated that clothing's thermal insulation is largely affected by wind speed, wind direction, human body movement, body posture and sweating, and such clothing physical parameters as fabric properties (e.g., thickness, weight, density and air permeability), clothing area factor and clothing design features (e.g., covering area, clothing combinations and apertures, wearing style, air gap size and distribution and air volume) [3-12]. Of all aforementioned factors, the air layer underneath the garment has a much greater effect on clothing insulation than basic fabric properties (e.g., thickness and thermal conductivity) [13,14].

Many documented studies have shown that clothing's thermal insulation is affected by the fit. Generally, loose-fitting clothing provides higher thermal insulation than tight-fitting clothing $[3,15]$. The clothing thermal insulation firstly increased with the air gap size (which was estimated by a circumference model), and it started to decrease as the air gap size exceeded a certain value, e.g., $7-8 \mathrm{~mm}[15,16]$. This was mainly due to the occurrence of natural/forced convection within the clothing microclimate. Recent advanced technology in the three dimensional (3D) scanning technique has made possible the study of air layer distribution in clothing and thereby, the relationship between clothing air gap and heat transfer parameters could be explored. The relationship between the air gap distribution and the burn pattern of male and female protective clothing exposed to flash fire was investigated using the 3D body scanning technology $[17,18]$. Findings demonstrated that skin burn injuries were found at body locations covered with small air gaps. Lu et al. [12,19] quantified 
the air layer of thermal protective coveralls and analyzed its relationship with the skin burn pattern under hot liquid spray exposures. In general, clothing with bigger air gaps provided better thermal protective performance. More severe skin burns were located at those body parts with smaller air gaps. Lee et al. [14] explored the relationship between the air volume and clothing thermal insulation using the phase-shifting moire topography. Thermal insulation at the upper body decreased when the microclimate air volume was higher than $7 \mathrm{dm}^{3}$. Li et al. [20] explored the relationship between the air gap and clothing thermal insulation and found that thermal insulation of shirts increased with air gap sizes but began to decrease when the air gap was higher than a certain value, although the cubic regression developed in their work was questionable from a physical viewpoint.

Almost all published studies on clothing heat transfer properties have been focused on Western-style clothing and thermal protective clothing. A limited number of studies have investigated thermal properties of non-Western clothing. Sung [13] determined thermal insulation of Korean costumes and found that the total thermal insulation of Korean costumes was normally greater than that of Western clothing at the lower body part. Al-ajmi et al. [21] measured thermal insulation of the Arabian Gulf traditional costumes and their clothing area factor. The generally accepted empirical formula for predicting clothing area factor based on Western style clothing was invalid for Arabian Gulf costumes. For non-Western clothing, the relation of clothing area factor to clothing insulation was quite different from those developed based on Western clothing [22]. Particularly, costumes from Chinese minority ethnic groups differed greatly in terms of clothing design structure, fitting and wearing styles compared with aforementioned garments. Western clothing is often designed to fit the body perfectly whereas Chinese ethnic minority costumes are loosely fitted. Thus, it is expected that the air gap distribution of Chinese costumes would differ distinctly from that of Western clothing and other non-Western clothing.

Presently, there is a lack of comprehensive study on the determination of thermal properties of Chinese style ethnic costumes. Moreover, the clothing local thermal properties have not been systematically examined yet. The determination of overall and local thermal properties of Chinese ethnic costumes contributes to the body of knowledge about improvement of overall and local thermal comfort of minority groups and thereby, their work performance and health could be enhanced. Hence, in this study, both the total and local air gap, clothing area factor and thermal insulation of 39 sets of Male Chinese ethnic costumes were determined using a 3D body scanner and a multi-segment thermal manikin. The relationship between clothing air gap/clothing area factor and thermal insulation was comprehensively explored. The results of this study further extended the clothing database presented in such standards as ASHRAE55-2013 [23], ISO 7730-2005 [1], and ISO 9920-2009 [24].

\section{Materials and Methods}

\subsection{Clothing Ensembles}

Thirty-nine sets of male ethnic costumes were selected from 39 Chinese ethnic minority groups. They were specially made based on the dimensions of the 'Newton' manikin and could be divided into 6 groups, according to their design features. Group 1 (G1) is two-piece garments with short-sleeve shirts or short dresses; group 2 (G2) is robes; group 3 (G3) includes short gowns and trousers or long dresses; group 4 (G4) consists of long-sleeve coats and trousers with decorations at the chest and the legs; group 5 (G5) comprises robes and trousers; group 6 (G6) is multilayer ensembles. The Bonan costume has two wearing ways: Bonan1 (i.e., wearing the left sleeve only) and Bonan2 (i.e., wearing both sleeves). Table 1 shows the physical properties of 39 sets of tested costumes. 
Table 1. Characteristics of the 39 sets of male minority ethnic costumes.

\begin{tabular}{|c|c|c|c|c|c|}
\hline Groups & Costume & Components & Materials & Fabric Thickness (mm) & Weight (g) \\
\hline \multirow{5}{*}{ G1 } & \multirow{2}{*}{$\mathrm{Li}$} & Short gown & $100 \%$ polyester & 0.58 & \multirow{2}{*}{512.2} \\
\hline & & Short dress & $100 \%$ polyester & 0.51 & \\
\hline & \multirow{2}{*}{ Russian } & Short sleeve shirt & $100 \%$ rayon & 0.25 & \multirow{2}{*}{477.6} \\
\hline & & Trousers & $100 \%$ polyester & 0.58 & \\
\hline & Dai & Short sleeve shirt, trousers & $100 \%$ rayon & 0.36 & 499.8 \\
\hline \multirow{5}{*}{ G2 } & Hezhe & Robe & $100 \%$ polyester & 1.62 & 395.8 \\
\hline & $\mathrm{Nu}$ & Robe & $55 \%$ flax, $45 \%$ cotton & 0.64 & 673.6 \\
\hline & Oroqen & Robe & $100 \%$ polyester & 0.81 & 743.6 \\
\hline & Mongolian & Robe & $100 \%$ polyester & 0.61 & 773.6 \\
\hline & Tibetan & Robe & $100 \%$ polyester & 0.38 & 1297.8 \\
\hline \multirow{14}{*}{ G3 } & Zhuang & Short gown, trousers & $100 \%$ polyester & 0.29 & 486.2 \\
\hline & Tajik & Short gown, trousers & $100 \%$ polyester & 0.60 & 992.0 \\
\hline & \multirow{2}{*}{ Pumi } & Short gown & $100 \%$ polyester & 0.86 & \multirow{2}{*}{812.0} \\
\hline & & Trousers & $100 \%$ polyester & 0.55 & \\
\hline & \multirow[b]{2}{*}{$\mathrm{Va}$} & Short gown & $100 \%$ polyester & 0.64 & \multirow[b]{2}{*}{657.4} \\
\hline & & Long dress & $78 \%$ polyester, $18 \%$ rayon, $4 \%$ spandex & 0.73 & \\
\hline & Jino & Short gown, trousers & $100 \%$ polyester & 0.56 & 670.4 \\
\hline & Sui & Short gown, trousers & $100 \%$ polyester & 0.70 & 761.4 \\
\hline & \multirow{2}{*}{ Gelao } & Short gown & $65 \%$ polyester, $35 \%$ flax & 0.26 & \multirow{2}{*}{470.6} \\
\hline & & Trousers & $100 \%$ polyester & 0.44 & \\
\hline & She & Short gown, trousers & $96 \%$ polyester, $4 \%$ spandex & 0.82 & 786.0 \\
\hline & & Short gown & $65 \%$ polyester, $35 \%$ flax & 0.72 & \\
\hline & Bouyei & Long dress (up) & $100 \%$ polyester & 0.50 & 1180.0 \\
\hline & & Long dress (down) & $100 \%$ polyester & 0.31 & \\
\hline & & Short gown, trousers & $96 \%$ polyester, $4 \%$ spandex & 0.26 & \\
\hline & Bai & Waistcoat & $100 \%$ polyester & 1.73 & 545.0 \\
\hline & Dongxiang & Short shirt, trousers & $100 \%$ polyester & 0.59 & \\
\hline & Dongxiang & Waistcoat & $98 \%$ polyester, $2 \%$ spandex & 0.63 & 845.0 \\
\hline & Yao & Long shirt, apron, trousers & $100 \%$ polyester & 0.64 & 997.8 \\
\hline & Dong & Short gown & $96 \%$ polyester, $4 \%$ spandex & 0.28 & \\
\hline & Dong & Waistcoat, trousers & $98 \%$ polyester, $2 \%$ spandex & 0.63 & 928.8 \\
\hline G4 & & Trousers & $65 \%$ polyester, $31 \%$ rayon, $4 \%$ spandex & 0.50 & \\
\hline & Nakhi & Short gown & $100 \%$ polyester & 0.61 & 806.4 \\
\hline & & Waistcoat & $100 \%$ polyester & 0.58 & \\
\hline & & Short gown & $54 \%$ polyester, $33 \%$ cotton, $13 \%$ polyamide & 0.31 & \\
\hline & Hani & Waistcoat, apron, trousers & $98 \%$ polyester, $2 \%$ spandex & 0.73 & 994.0 \\
\hline & $\mathrm{H}_{1 \mathrm{i}}$ & Long shirt, trousers & $100 \%$ polyester & 0.62 & \\
\hline & Hu1 & Waistcoat & $100 \%$ polyester & 0.66 & 975.6 \\
\hline & Uyohur & Short gown, trousers & $96 \%$ polyester, $4 \%$ spandex & 0.30 & \\
\hline & Uygnur & Long waistcoat & $10 \%$ polyester, $85 \%$ cotton, $5 \%$ flax & 0.70 & 732.4 \\
\hline & Miว & Robe & $50 \%$ polyester, $50 \%$ polyamide & 0.43 & \\
\hline & Miao & Waistcoat, trousers & $98 \%$ polyester, $2 \%$ spandex & 0.63 & 934.6 \\
\hline & Daur & Robe & $96 \%$ polyester, $4 \%$ spandex & 0.85 & \\
\hline & Daur & Trousers & $96 \%$ polyester, $4 \%$ spandex & 0.60 & 1066.0 \\
\hline & Mulao & Robe & $100 \%$ rayon & 0.48 & 6698 \\
\hline & Mulao & Trousers & $100 \%$ polyester & 0.30 & 669.8 \\
\hline & Xibe & Robe, trousers & $96 \%$ polyester, $4 \%$ spandex & 0.81 & 1213.6 \\
\hline & & Robe & $100 \%$ rayon & 0.47 & \\
\hline G5 & Manchu & Trousers & $100 \%$ polyester & 0.44 & 887.8 \\
\hline & & Robe & $10 \%$ polyester, $85 \%$ cotton, $5 \%$ flax & 1.19 & \\
\hline & Uzbek & Short shirt & $100 \%$ rayon & 0.22 & 1120.4 \\
\hline & & Trousers & $98 \%$ polyester, $2 \%$ spandex & 0.57 & \\
\hline & & Short shirt & $100 \%$ polyester & 0.60 & \\
\hline & Kazakh & Robe, trousers & $100 \%$ polyester & 0.63 & 1153.6 \\
\hline & Derung & Robe, trousers & $100 \%$ polyester & 0.55 & \\
\hline & Derung & Short shirt & $100 \%$ polyester & 0.60 & 1262.0 \\
\hline & Tuiii & Short shirt & $55 \%$ flax, $45 \%$ cotton & 0.60 & 9244 \\
\hline & Iujia & Short gown, trousers & $98 \%$ cotton, $2 \%$ spandex & 0.52 & 924.4 \\
\hline & & Trousers & $100 \%$ polyester & 0.62 & \\
\hline & $\mathrm{Tu}$ & Short shirt, short gown, waistcoat & $98 \%$ cotton, $2 \%$ spandex & 0.63 & 1506 \\
\hline & & Short gown, dress smock & $100 \%$ polyester & 0.537 & \\
\hline G6 & Yi & Trousers & $96 \%$ polyester, $4 \%$ spandex & 0.133 & 903.0 \\
\hline & Bonan & Long shirt, robe, trousers & $100 \%$ polyester & 0.59 & 1748.6 \\
\hline & & Robe & $96 \%$ polyester, $4 \%$ spandex & 0.84 & 17888 \\
\hline & Qiang & Fur waistcoat & $96 \%$ polyester, $4 \%$ spandex & 5.09 & $1 / 88.8$ \\
\hline & & Trousers & $62 \%$ rayon, $38 \%$ polyester & 0.65 & \\
\hline
\end{tabular}




\subsection{Thermal Manikin}

A 34-segment 'Newton' thermal manikin (Thermetrics LLC, Seattle, WA, USA) was used to determine the total and local thermal insulation. The manikin's segmental surface temperature or the heating power can be controlled individually. Among all 34 body segments, two segments were designed for seating purposes and thus the heating function of the two segments were disabled in our study. The remaining 32 segments were divided into 11 main body parts [25]. Total and local thermal insulations at those 11 body parts were reported accordingly. The manikin surface temperature and the heat flux generated during the experiment at each body segment were recorded by the ThermDAC ${ }^{\circledR}$ software (Thermetrics LLC, Seattle, WA, USA).

\subsection{Three-Dimensional Body Scanner}

To capture the 3D body shape and clothing profile, a VITUS Smart 3D whole-body laser scanner (Human Solutions $\mathrm{GmbH}$, Kaiserslautern, Germany) was used. This scanner is a non-contact optical measuring system capable of rapidly generating a $360^{\circ}$ representation of the surface geometry of an object. The scanned object, formed by point cloud data, can be rotated, resized and sliced. A model mannequin, showing almost the same size of the 'Newton' thermal manikin, was used to represent the clothing air layer between the thermal manikin and tested clothing ensembles. The nude mannequin was first scanned, and then the dressed mannequin was scanned with the same position and posture. Each garment was scanned three times, by dressing and undressing. The raw data with a format of ".wrl" were outputted for the determination of the air gap and the clothing area factor.

\subsection{Determination of the Air Gap and Clothing Area Factor}

To determine the clothing air gap, as well as to compute the clothing area factor, the Geomagic Qualify 12.0 software (Geomagic Inc., Morrisville, NC) was used for data analysis. There were some missing areas in the scans where cameras could not capture the data. To accurately determine the air gap between clothing and the manikin body, an integral and smooth body surface was necessary. The scan data were firstly meshed, and then they were rewrapped, and the holes were filled by using the 'Fill Holes' tools. Subsequently, the healing wizard function was applied, and the optimized high-quality mesh model (including holes filling, mesh repair, smoothing and scrubbing functions, etc.) was exported (see Figure 1a,b).

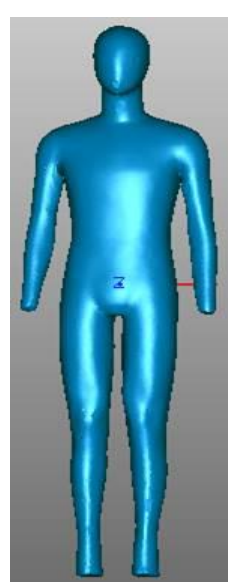

(a)

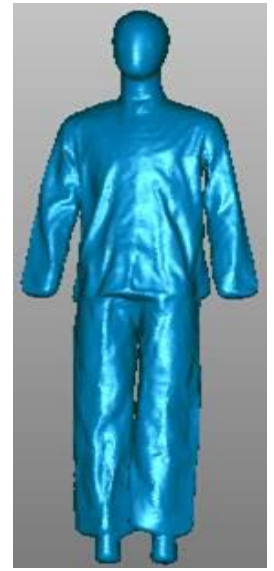

(b)

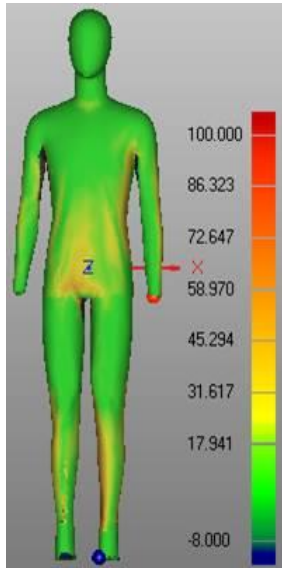

(c)

Figure 1. Determination of the air gap distribution: (a) scanned nude mannequin; (b) scanned clothed mannequin, and (c) air gap distribution.

To calculate the air gap size, air volume and clothing area factor, both nude and clothed scans were required to be overlapped and aligned as accurately as possible. Accurate alignment required 
minimal changes in the position of the nude and clothed manikin between scans. The two scans could be aligned by several points of nodules and then slightly shifted the $\mathrm{x}, \mathrm{y}$ and $\mathrm{z}$ coordinates of the clothed scan, to perfectly align the two scans by the alignment algorithm. Body parts were sliced according to the body separation of the thermal manikin. Both total and local air gap distributions over the body surface were presented with different color bars (see Figure 1c). In addition, both total and local air volumes entrapped in clothing were calculated. The surface area of the whole body and local body parts was also reported.

\subsection{Calculations}

Total thermal insulation of the boundary air layer and each costume was calculated by the parallel method, using the following equation [24].

$$
I_{t}=\frac{\left(T_{\text {manikin }}-T_{a}\right) \times A}{0.155 \times \sum_{i=1}^{32}\left(H_{i} \times A_{i}\right)}
$$

where $I_{t}$ is the clothing total thermal insulation, clo; $A_{i}$ is the surface area of the segment $i, \mathrm{~m}^{2} ; A$ is the total surface area of the manikin, $\mathrm{m}^{2} ; T_{\text {manikin }}$ is the manikin surface temperature $\left({ }^{\circ} \mathrm{C}\right) ; T_{a}$ is the air temperature, ${ }^{\circ} \mathrm{C}$; and $H_{i}$ is the observed dry heat loss at the segment, $i, \mathrm{~W} / \mathrm{m}^{2}$.

Local thermal insulation of each body part was calculated by the global method [24], as shown in Equation (2) [24]

$$
I_{t, j}=\frac{\left(\sum \frac{A_{i} \times T_{\text {manikin, }, i}}{A_{j}}\right)-T_{a}}{0.155 \times \sum \frac{A_{i} \times H_{i}}{A_{j}}}
$$

where $I_{t, j}$ is the local thermal insulation of the manikin segment, $i$ and the main body part, $j$, respectively, clo; $A_{i}$ and $A_{j}$ are the surface areas of the segment, $i$, and the body part, $j$, respectively, $\mathrm{m}^{2} ; T_{\text {manikin, } i}$ and $T_{a}$ are the manikin surface temperature of the segment, $i$, and the air temperature respectively, ${ }^{\circ} \mathrm{C}$; and $H_{i}$ is the observed dry heat loss at the segment $i, \mathrm{~W} / \mathrm{m}^{2}$.

Clothing area factor of each ethnic costume was calculated by using the following equation [24].

$$
f_{c l}=\frac{A_{c l}}{A_{n}}
$$

where $f_{c l}$ is the clothing area factor, dimensionless; $A_{c l}$ is the surface area of the clothed mannequin, $\mathrm{m}^{2}$; and $A_{n}$ is the surface area of the nude mannequin, $\mathrm{m}^{2}$.

The intrinsic thermal insulation of each costume was calculated by using Equation (4) [24].

$$
I_{c l}=I_{t}-\frac{I_{a}}{f_{c l}}
$$

where $I_{c l}$ is the intrinsic thermal insulation, clo; and $I_{a}$ is the boundary air layer's thermal insulation, clo.

\subsection{Experimental Protocol and Test Conditions}

All thermal manikin measurements strictly followed the ISO 15831-2004 standard [26]. The constant temperature mode (i.e., $T_{\text {manikin }}=34.0^{\circ} \mathrm{C}$ ) was used. The relative humidity $(\mathrm{RH})$ and the air velocity inside the climatic chamber were $50 \pm 5 \%$ and $0.4 \pm 0.1 \mathrm{~m} / \mathrm{s}$, respectively. For the selected ethnic costumes, the total thermal insulation, local thermal insulation, and the intrinsic thermal insulation were calculated. The data acquisition frequency was $30 \mathrm{~s}$. The detailed procedure of the determination of the air gap and clothing area factor was described in Section 2.4. Both manikin tests and 3D scanning tests for each ethnic costume were performed three times. 


\section{Results}

The boundary air layer's thermal insulation was $0.50 \mathrm{clo}$, which was determined on the nude thermal manikin at $0.4 \pm 0.1 \mathrm{~m} / \mathrm{s}$ wind. Table 2 presents the air volume, air gap size, clothing area factor, total thermal insulation, and intrinsic thermal insulation of the 39 ethnic costumes. The air volume lies in the range of $23.0 \sim 93.1 \mathrm{dm}^{3}$, the average air gap ranges is $15.0 \sim 51.4 \mathrm{~mm}$, and the clothing area factor is in the range of 1.11 1.70. The clothing total thermal insulation has a range of $0.81 \sim 1.48$ clo, and the intrinsic thermal insulation is $0.35 \sim 1.18$ clo. The Tibetan costume has the largest air layer (the air volume and air gap size) and clothing area factor, whereas the Li costume shows the smallest air layer and clothing area factor. The Bonan2 exhibits the largest total thermal insulation and intrinsic thermal insulation, whereas the Li shows the lowest thermal insulation. In addition, G1 shows the minimal thermal insulation, while G6 exhibits the greatest thermal insulation.

Table 2. Air volume, air gap size, clothing area factor, total thermal insulation, and intrinsic thermal insulation of the selected ethnical costumes.

\begin{tabular}{|c|c|c|c|c|c|c|}
\hline Groups & Costume & $V_{c l}\left(d^{3}\right)$ & $d_{a i r}(\mathrm{~mm})$ & $f_{c l}$ & $I_{t}$ (clo) & $I_{c l}$ (clo) \\
\hline \multirow{3}{*}{ G1 } & $\mathrm{Li}$ & 22.99 & 15.00 & 1.11 & 0.81 & 0.35 \\
\hline & Russian & 27.98 & 16.23 & 1.18 & 0.86 & 0.44 \\
\hline & Dai & 24.41 & 17.42 & 1.22 & 0.92 & 0.51 \\
\hline \multirow{5}{*}{ G2 } & Hezhe & 33.21 & 21.67 & 1.22 & 0.91 & 0.50 \\
\hline & $\mathrm{Nu}$ & 42.07 & 25.92 & 1.34 & 0.94 & 0.56 \\
\hline & Oroqen & 44.30 & 30.05 & 1.31 & 0.95 & 0.56 \\
\hline & Mongolian & 46.00 & 29.05 & 1.30 & 1.04 & 0.65 \\
\hline & Tibetan & 93.06 & 51.39 & 1.70 & 1.17 & 0.88 \\
\hline \multirow{9}{*}{ G3 } & Zhuang & 26.19 & 16.99 & 1.23 & 0.99 & 0.59 \\
\hline & Tajik & 30.76 & 19.60 & 1.21 & 0.99 & 0.58 \\
\hline & Pumi & 30.30 & 17.19 & 1.25 & 1.01 & 0.61 \\
\hline & $\mathrm{Va}$ & 49.43 & 27.08 & 1.22 & 1.01 & 0.60 \\
\hline & Jino & 28.06 & 16.27 & 1.23 & 1.03 & 0.62 \\
\hline & Sui & 33.61 & 18.90 & 1.24 & 1.05 & 0.64 \\
\hline & Gelao & 28.93 & 17.79 & 1.24 & 1.01 & 0.61 \\
\hline & She & 20.07 & 12.67 & 1.14 & 1.05 & 0.61 \\
\hline & Bouyei & 84.67 & 46.54 & 1.67 & 1.10 & 0.80 \\
\hline \multirow{9}{*}{ G4 } & Bai & 27.95 & 15.53 & 1.19 & 1.05 & 0.63 \\
\hline & Dongxiang & 31.07 & 18.15 & 1.24 & 1.07 & 0.67 \\
\hline & Yao & 32.29 & 18.62 & 1.24 & 1.08 & 0.68 \\
\hline & Dong & 33.60 & 19.64 & 1.15 & 1.10 & 0.66 \\
\hline & Nakhi & 34.83 & 19.70 & 1.27 & 1.11 & 0.71 \\
\hline & Hani & 36.37 & 20.53 & 1.23 & 1.17 & 0.76 \\
\hline & Hui & 38.52 & 20.84 & 1.24 & 1.09 & 0.68 \\
\hline & Uyghur & 30.02 & 16.79 & 1.19 & 1.10 & 0.67 \\
\hline & Miao & 50.18 & 27.41 & 1.23 & 1.23 & 0.82 \\
\hline \multirow{8}{*}{ G5 } & Daur & 32.70 & 18.61 & 1.22 & 1.06 & 0.65 \\
\hline & Mulao & 33.57 & 19.45 & 1.27 & 1.13 & 0.73 \\
\hline & Xibe & 64.02 & 35.60 & 1.38 & 1.13 & 0.77 \\
\hline & Manchu & 60.16 & 34.63 & 1.42 & 1.16 & 0.81 \\
\hline & Uzbek & 35.85 & 19.47 & 1.15 & 1.18 & 0.74 \\
\hline & Kazazh & 39.89 & 20.56 & 1.19 & 1.21 & 0.79 \\
\hline & Drung & 47.83 & 27.08 & 1.31 & 1.25 & 0.86 \\
\hline & Tujia & 35.19 & 20.58 & 1.24 & 1.19 & 0.78 \\
\hline \multirow{5}{*}{ G6 } & $\mathrm{Tu}$ & 45.72 & 25.20 & 1.25 & 1.26 & 0.86 \\
\hline & Yi & 74.20 & 51.40 & 1.35 & 1.28 & 0.91 \\
\hline & Bonan1 & 71.39 & 39.55 & 1.65 & 1.33 & 1.02 \\
\hline & Bonan2 & 65.07 & 40.43 & 1.65 & 1.48 & 1.18 \\
\hline & Qiang & 54.99 & 29.03 & 1.31 & 1.36 & 0.98 \\
\hline
\end{tabular}




\subsection{Thermal Insulation, Clothing Area Factor and Average Air Gap}

The relationship between the clothing total thermal insulation and the air gap (i.e., average air gap size and air volume) is presented in Figure 2. It is evident that the clothing total thermal insulation first increases with the increasing of air gap size (air volume), and it begins to decrease when the air volume (or the mean air gap size) reaches $55.8 \mathrm{dm}^{3}$ (or $37.8 \mathrm{~mm}$ ). To ensure that the total thermal insulation equals that of the boundary air layer (i.e., $0.50 \mathrm{clo}$ ) when no clothing layer presents, the regression equation was forced to go through the point $(0,0.50)$.

The coefficient factor $R^{2}$ is higher than 0.52 and the equations read as follows:

$$
\begin{aligned}
& I_{t}=-0.00016 \times V_{c l}^{2}+0.0222 \times V_{c l}+0.50 \\
& I_{t}=-0.00047 \times d_{\text {air }}^{2}+0.0376 \times d_{\text {air }}+0.50
\end{aligned}
$$

where $I_{t}$ is the clothing total thermal insulation (clo); $V_{c l}$ is the clothing air volume $\left(\mathrm{dm}^{3}\right)$; and $d_{a i r}$ is the average air gap size $(\mathrm{mm})$.
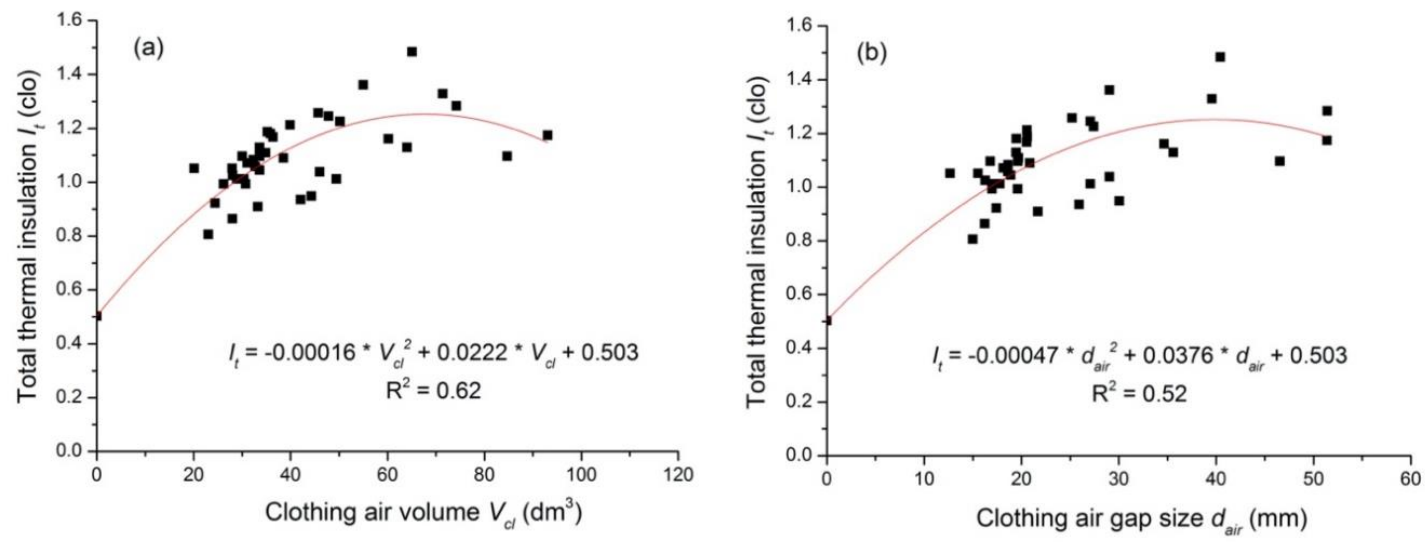

Figure 2. Relationship between the clothing total thermal insulation and (a) the air volume; (b) the air gap size.

Figure 3 shows the relationship between clothing intrinsic thermal insulation and clothing area factor. In order to ensure that the clothing area factor equals the unity if there is no clothing dressed, the regression equation was forced to pass the point $(0,1.0)$. The coefficient factor $R^{2}$ is 0.53 , and the equation reads as follows:

$$
f_{c l}=1.00+0.42 \times I_{c l}
$$

where $I_{c l}$ is the clothing intrinsic thermal insulation (clo); and $f_{c l}$ is the clothing area factor, dimensionless.

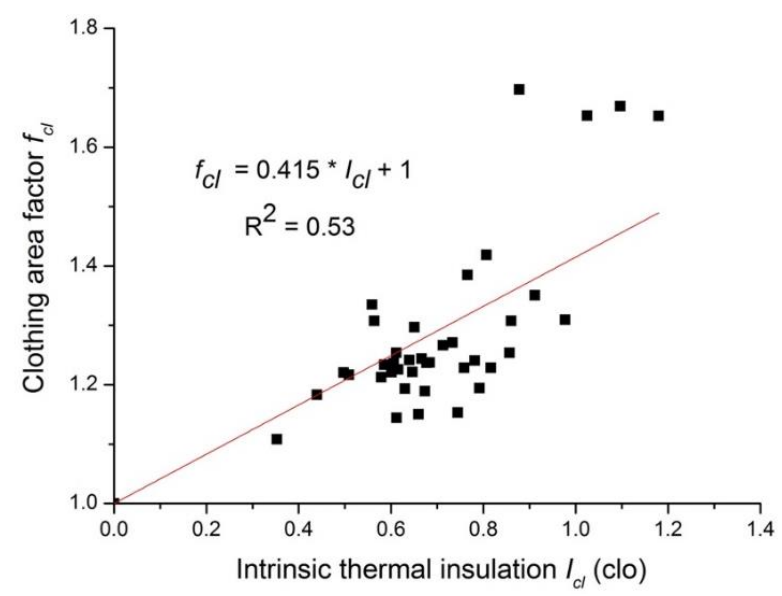

Figure 3. Relationship between the clothing intrinsic thermal insulation and the clothing area factor. 
Generally, the higher the clothing area factor, the larger the clothing insulation. Of all 39 ethnic costumes, the Tibetan costume had the largest $f_{c l}$ but a relatively small $I_{c l}$. If it was excluded from the database (because Tibetan costume violated the generally accepted relation), then Equation (7) can be expressed as follows $\left(R^{2}=0.58\right)$.

$$
f_{c l}=1.00+0.40 \times I_{c l}
$$

As is shown in Figure 2, the clothing thermal insulation might decrease if the air gap is larger than a certain value, e.g., the thermal insulation of the Tibetan costume is low although its air layer is the largest among all studied costumes. The parabolic equation was developed to characterize the relationship between $I_{c l}$ and $f_{c l}$ (see Figure 4), and it reads as follows:

$$
I_{c l}=-6.543 \times f_{c l}^{2}+9.57 \times f_{c l}-3.024
$$

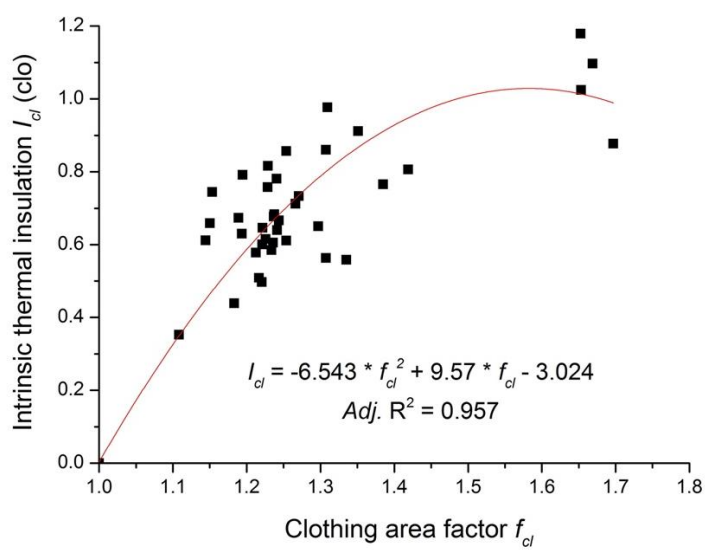

Figure 4. Parabolic correlation of the clothing area factor with the intrinsic thermal insulation.

\subsection{Clothing Local Thermal Insulation and Local Air Gap}

In this study, the head, hands and feet were not covered by clothing. Thus, only eight body parts (i.e., arms, chest, shoulders, abdomen, back, pelvis, thighs and lower legs) were investigated. Figure 5 shows the relationship between the local thermal insulation and local air gap for eight body parts. In general, the local thermal insulation increases with the increasing local air gap size, while it turns to decrease as the local air gap size exceeds a certain level (e.g., the turning point for the thigh and the lower leg is 35.7 and $40.8 \mathrm{~mm}$, respectively). The results are presented in Table 3 . In order to ensure that the $I_{t, j}$ equals the local boundary air layer's thermal insulation if no clothing is presented, the regression equation was forced to pass the point $\left(0, I_{a, j}\right)$ for all body parts. The prediction quality is judged by the correlation factor $\mathrm{R}^{2}$. The equation reads as follows:

$$
I_{t, j}=a \times d_{a i r, j}^{2}+b \times d_{a i r, j}+I_{a, j}
$$

where $I_{t, j}$ is the local clothing thermal insulation (clo); $I_{a, j}$ is the local insulation of the boundary air layer (clo); and $d_{a i r, j}$ is the local air gap size (mm).

Table 3. Coefficients of the regression equations for eight different body parts.

\begin{tabular}{cccccc}
\hline Body Part & $\mathbf{a}$ & $\mathbf{b}$ & $\boldsymbol{I}_{a, \boldsymbol{i}}$ & $\mathbf{R}^{\mathbf{2}}$ & Turning Point \\
\hline Arms & -0.0007 & 0.0615 & 0.490 & 0.55 & 43.9 \\
Chest & -0.0087 & 0.251 & 0.504 & 0.70 & 14.4 \\
Shoulder & -0.0204 & 0.287 & 0.632 & 0.54 & 7.0 \\
Abdomen & -0.0041 & 0.188 & 0.497 & 0.34 & 22.9 \\
Back & -0.003 & 0.158 & 0.575 & 0.39 & 26.3 \\
Pelvis & -0.008 & 0.28 & 0.537 & 0.16 & 17.9 \\
Thigh & -0.0014 & 0.1 & 0.452 & 0.30 & 35.7 \\
Lower leg & -0.0004 & 0.0326 & 0.480 & 0.21 & 40.8 \\
\hline
\end{tabular}



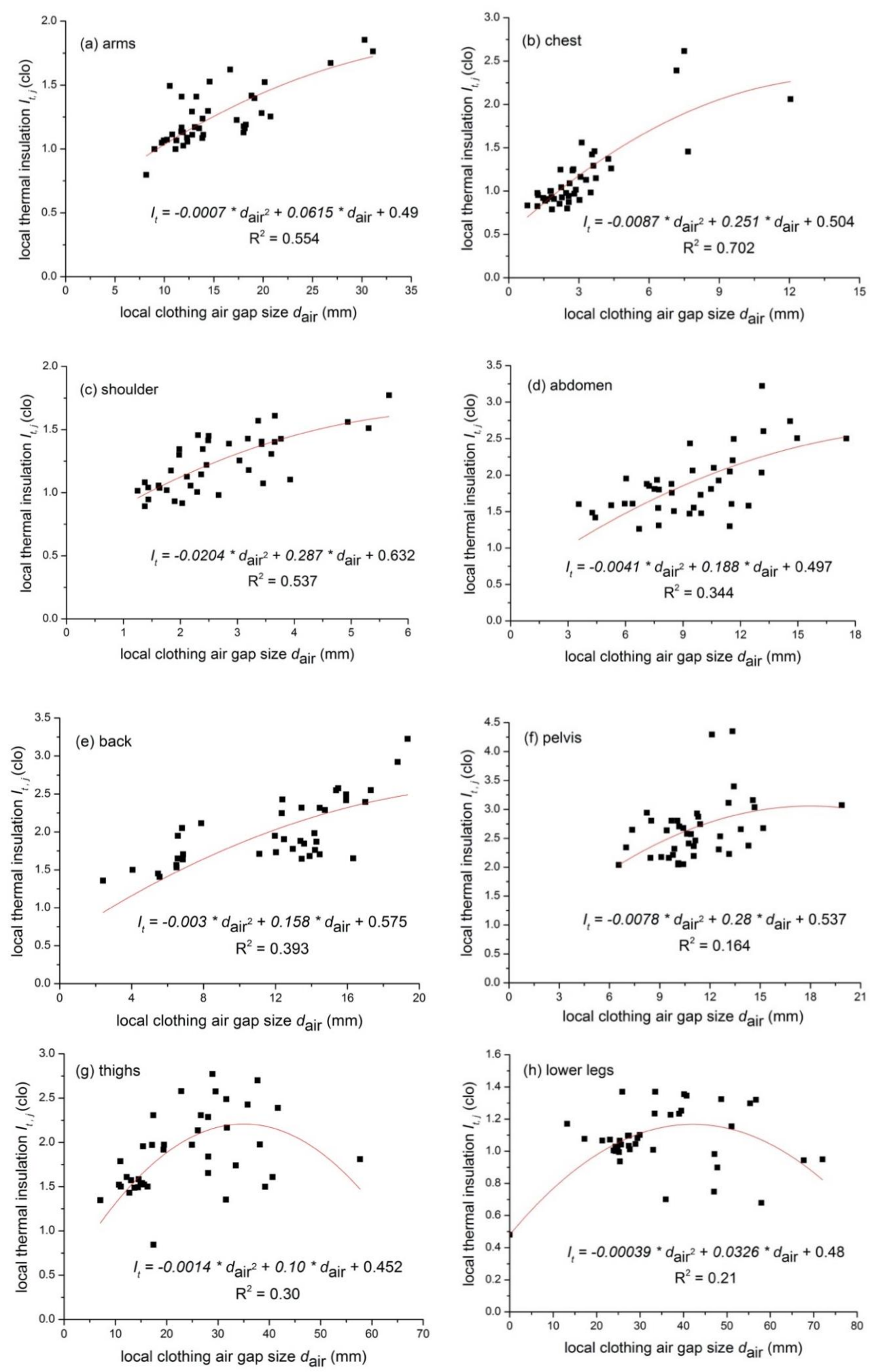

Figure 5. Relationships between the local $I_{c l}$ and the local $d_{\text {air }}$ for different body parts. (a) arms; (b) chest; (c) shoulders; (d) abdomen; (e) back; (f) pelvis; (g) thighs; and (h) lower legs.

\subsection{Local Intrinsic Thermal Insulation and Local Clothing Area Factor}

Figure 6 presents the relationships between the local intrinsic thermal insulation and local clothing area factor for eight body parts. Eight linear regression equations were developed and the results are 
shown in Table 4 . The regression equation was also forced to go through the point $(0,1)$. The equation reads as follows:

$$
f_{c l, j}=1.00+a \times I_{c l, j}
$$

where $I_{c l, i}$ is the local clothing intrinsic thermal insulation at the body part, $j$, clo; and $f_{c l, j}$ is the local clothing area factor at the body part, $j$.
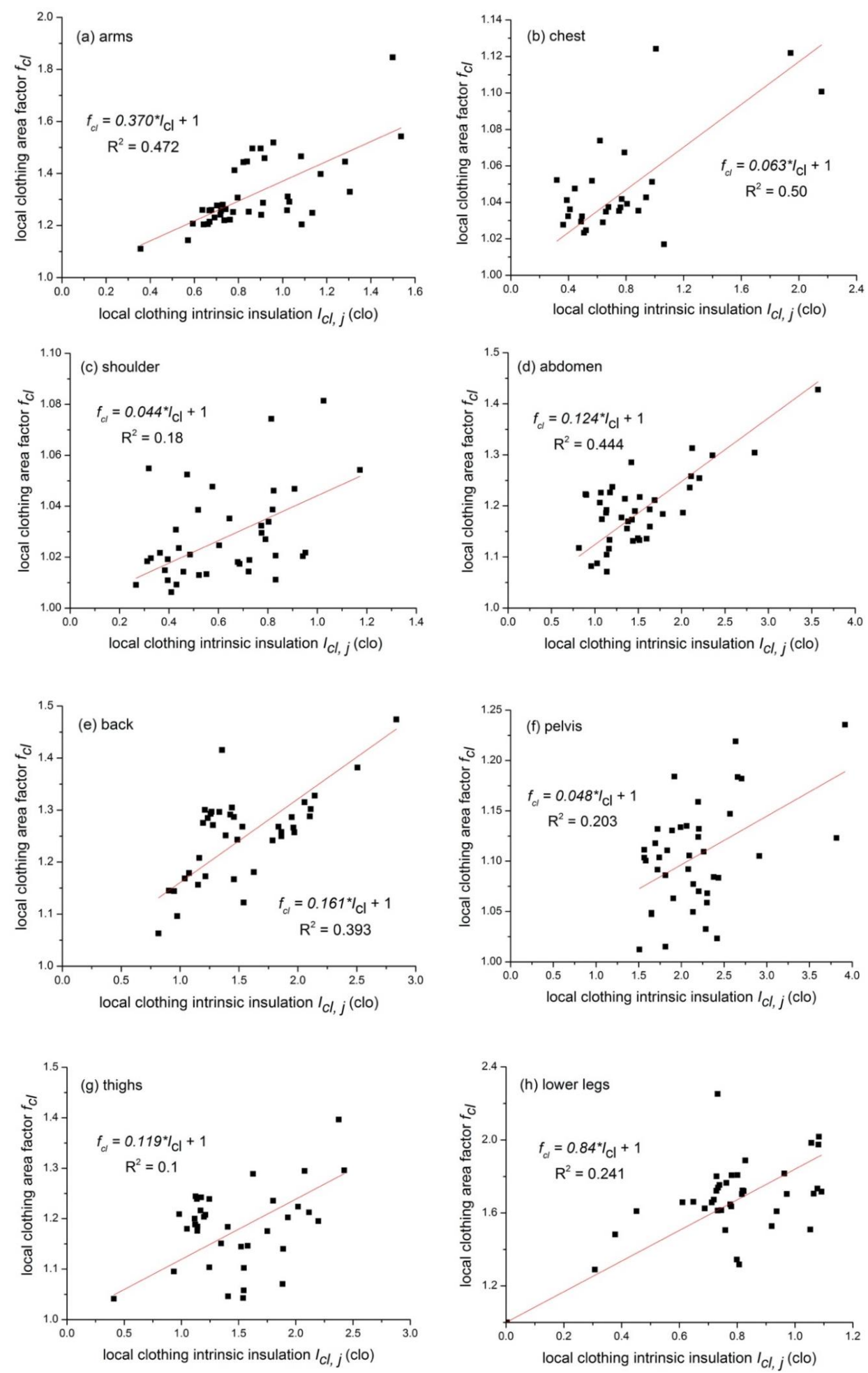

Figure 6. Relationships between the local $I_{c l}$ and local $f_{c l}$ for different body parts. (a) arms; (b) chest; (c) shoulders; (d) abdomen; (e) back; (f) pelvis; (g) thighs; and (h) lower legs. 
Table 4. Linear regression equations of local $f_{c l}$ and $I_{c l}$ for different body parts.

\begin{tabular}{ccc}
\hline Body Part & $\mathbf{a}$ & $\mathbf{R}^{\mathbf{2}}$ \\
\hline Arms & 0.370 & 0.47 \\
Chest & 0.063 & 0.50 \\
Shoulder & 0.044 & 0.18 \\
Abdomen & 0.124 & 0.44 \\
Back & 0.161 & 0.39 \\
Pelvis & 0.048 & 0.20 \\
Thigh & 0.119 & 0.04 \\
Lower leg & 0.84 & 0.24 \\
\hline
\end{tabular}

\section{Discussion}

In the present study, both total and local clothing heat transfer properties (i.e., thermal insulation, air gap, and clothing area factor) of 39 ethnic costumes were investigated. Due to the garment construction varieties, the total thermal insulation varied from 0.81 to $1.48 \mathrm{clo}$, and the intrinsic thermal insulation was found in the range of $0.35 \sim 1.18$ clo. G1 shows the minimal thermal insulation, while G6 exhibits the maximum thermal insulation. This is because costumes in G1 had the smallest body covering area while G6 had multiple clothing layers. The Bonan costume had two wearing styles. The costume in different wearing styles showed different thermal insulation values, e.g., a lower thermal insulation was presented if only one sleeve of the Bonan costume was worn. This finding is in line with Li et al.'s study [5], in which the thermal insulation of the Tibetan robe ensemble was determined in three different wearing styles. In our study, the air volume and the average air gap size were in the range of $23.0 \sim 93.1 \mathrm{dm}^{3}$ and 15.0 51.4 mm, respectively, and the clothing area factor was 1.11 1.70. The Tibetan costume showed the largest air layer and clothing area factor, whereas the Li costume presented the smallest air layer and clothing area factor. According to the clothing database of ISO 9920-2009 [24] and ASHARE 55-2013 [23], it was found that the thermal insulation and clothing area factor of male Chinese ethnic costumes were in between those of the Western clothing and the non-Western clothing.

The effect of garment fit on total thermal insulation has been explored. It was found that the total thermal insulation increased with the increasing air gap size (or air volume), and the increase rate gradually decreased. With the further increasing of the air gap size or the air volume, the total thermal insulation started to decrease. This is consistent with the findings of previous studies $[3,14,15,27]$, i.e., when the air gap is small, the increase in the air gap size or the air volume raises the total thermal insulation because of more entrapped still air. If the air gap reached a certain limit, natural convection and air circulation in the microclimatic air layers occurred. The rate of ventilation depends on the clothing fit, with more ventilation occurring in loose-fitting clothing than in tight-fitting clothing [28]. Therefore, the increment of the thermal insulation with the air gap gradually decreased and a further increasing of the air gap could cause a drop in the total thermal insulation. In addition, the turning point of the air volume and the air gap size to induce a dropping in the total thermal insulation was $55.8 \mathrm{dm}^{3}$ and $37.8 \mathrm{~mm}$, respectively. These two reported values were different from the previous studies. Lee et al. [14] found that clothing's thermal insulation began to decrease when the air volume was larger than $7 \mathrm{dm}^{3}$. Thermal insulation turned to decrease as the air gap size was larger than $10 \mathrm{~mm}$ [15]. However, it should be noted that Chen et al. [15] investigated the effect of garment fit on the upper body's total thermal insulation. There was no clothing or the same clothing dressed at the lower body. In Chen et al.'s study [15], the air gap and thermal insulation at the upper body were estimated using a circumference model. This may introduce a big error to quantitatively characterize the relationship between the air gap size and clothing thermal insulation. The 3D scanning technique has been recognized as the most reproducible and accurate method for measuring the microclimate air volume among the widely used approaches [29]. Although there are many studies on the air gap determination of the full-body clothing ensemble using 3D body scanning $[18,19,30]$, there is no solid air gap data reported for robes or the dress style ensembles. In this study, we investigated the thermal 
insulation and quantitatively determined the air gap distribution of various costumes using the 3D body scanning technology. Thus, the results obtained in this study are systematic and persuasive.

Unlike the air layer averaged along the body circumference obtained by the circumference model or the total air volume determined by the vacuum suit method, the application of 3D body scanning could accurately show the air gap distribution and figure out the occurrence locations of convection within the clothing system. The relationship between the local air gap and the local thermal insulation at different body parts was developed. All eight body parts showed significant parabolic correlations but coefficients were different. The local thermal insulation increased with the increasing air gap size, and it began to drop as the air gap size exceeded a certain value. This is similar to the relationship found between the total thermal insulation and the average air gap size. The turning point for the eight body parts was in the range of 7.0 (shoulders) $~ 43.9 \mathrm{~mm}$ (arms). The air gap size at the chest and shoulders was lower than that at the arms, thighs and lower legs, which was in good agreement with Lu et al.'s study [19]. It seems that the turning point for each body part was linearly related to the corresponding average air gap $\left(y=0.9996 x+12.103, R^{2}=0.66\right)$. In general, body regions with larger air gap sizes had a larger turning point value. For such body parts as the lower body, loose fitting garments permit a larger extent of air convection and ventilation, and thus the local thermal insulation at those regions was small. The relationship between the thermal insulation and the air gap at different body parts is vital to develop models for predicting human local thermal comfort while wearing ethnic costumes.

With regard to the relationship between local thermal insulation and local air gap size as shown in Table 3, the upper body regions (i.e., arms, chest, shoulder, abdomen and back) showed a higher $\mathrm{R}^{2}$ than that of the lower body (i.e., the pelvis, thigh and lower legs). One possible reason is that the pelvis, thighs or lower legs were always covered by multilayer clothing (e.g., garments in G5 and G6). This will add the insulation but may not greatly change the air gap size, and thus decrease the correlation factor (i.e., $\mathrm{R}^{2}$ values) of the regression. Considering the long robe/dress style of tested costumes, there might be systematic errors in the calculation of air gaps at thighs and lower legs. In addition, some tested costumes consisted of waist belts, which reduced air gaps at the abdomen and the back. Nevertheless, this may not have reduced the local thermal insulation due to the adding belt, and thus affected the changing trend at those body regions. To clarify this influencing factor, the regression analysis of costumes with and with no belt was performed and the results are shown in Figure 7 and Table 5. It is evident that this improved the correlation factor $R^{2}$ (e.g., 0.60 and 0.73 for the abdomen and the back when the belt was worn). As there was no pronounced change in the air gap at the back among all costumes, only a linear relationship was developed. In the specified air gap intervals, thermal insulation increased with the air gap.
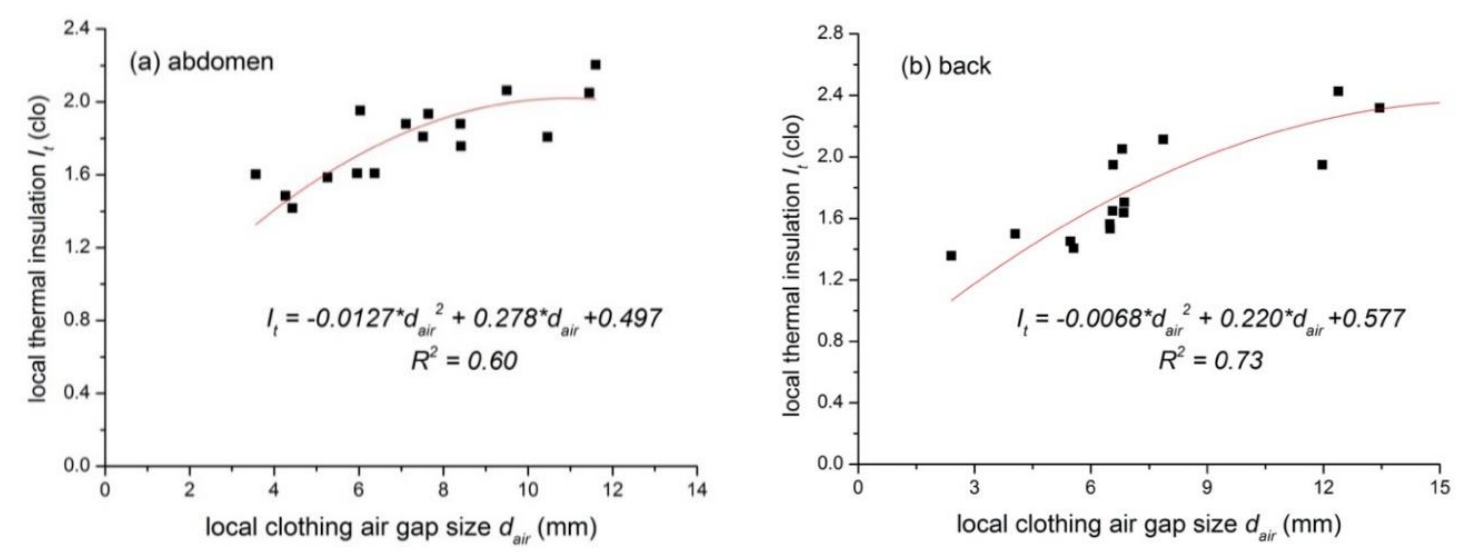

Figure 7. Relationship between the air gap size and the thermal insulation at the abdomen (a) and the back (b) with the waist belt. 
Table 5. Coefficients of regression equations for the abdomen and back.

\begin{tabular}{cccccc}
\hline Body Part & & $\mathbf{a}$ & $\mathbf{b}$ & $\boldsymbol{I}_{a, i}$ & $\mathbf{R}^{2}$ \\
\hline \multirow{2}{*}{ Abdomen } & No belt & -0.0009 & 0.139 & 0.497 & 0.45 \\
& With belt & -0.0127 & 0.278 & 0.497 & 0.60 \\
\hline \multirow{2}{*}{ Back } & No belt & 0 & 0.104 & 0.575 & 0.44 \\
& With belt & -0.0068 & 0.2203 & 0.575 & 0.73 \\
\hline
\end{tabular}

The correlation of clothing area factor $f_{c l}$ with the intrinsic thermal insulation $I_{c l}$ was also developed. The equation reads $f_{c l}=1.00+0.42 \times I_{c l}\left(0.3\right.$ clo $<I_{c l}<1.2$ clo $)$. McCullough developed a similar equation based on Western style clothing and this equation was later adopted by ISO 9920-2009 [24]. The equation reads $f_{c l}=1.00+0.31 \times I_{c l}\left(0.3 \mathrm{clo}<I_{c l}<1.7 \mathrm{clo}\right)$. It is obvious that our equation is different from McCullough's equation. This is in line with studies of Al-ajmi et al. [21] and Havenith et al. [22], who found the coefficient was ranged from 0.447 to 0.460 . It should be noted that the intrinsic thermal insulation was calculated based on a cylindrical clothing model. The model assumed that clothing was worn as cylinders around different human body parts (which were also described as cylinders with different diameters). This seems true for typical Western style clothing. Non-Western costumes such as Arabian Gulf costumes and Chinese ethnic costumes chosen for this study had a loose fit and long robes/dress styles, so it was expected that there was air movement underneath such loose fitting costumes. Hence, the still boundary air layer may only be around the legs rather than spread all over the outer costumes. Therefore, a large error may exist when calculating the clothing intrinsic thermal insulation. With regard to practical application, the determination of intrinsic thermal insulation should consider the garment construction as well as fabric properties such as drapability.

\section{Conclusions}

The present study investigated both the total and local dry heat transfer properties of 39 sets of male Chinese ethnic costumes. Results demonstrated that the total thermal insulation first increased with the air gap size or air volume, and with a further increasing of the air gap size or the air volume, the thermal insulation turned to decrease. The turning point of the air gap size and the air volume was $37.8 \mathrm{~mm}$ and $55.8 \mathrm{dm}^{3}$ respectively. The correlation of local thermal insulation with the local air gap showed similar changing trends. Different body parts exhibited similar regression equations but the coefficients were different. A linear relationship between the clothing area factor and the intrinsic thermal insulation was also developed. It was found that the equation developed for Male Chinese ethnic costumes was different from the one established based on Western clothing. The results provide an extensive database of heat transfer properties of non-Western style garments, which is expected to be a valuable addition to the ASHRAE Standard 55-2013, ISO Standard 7730-2005, and ISO Standard 9920-2009. The research findings will also be helpful to develop heat transfer models for predicting local thermal comfort of Chinese minority groups while wearing ethnic costumes.

Author Contributions: Conceptualization, F.W.; data curation, Y.K. and F.W.; formal analysis, F.W.; funding acquisition, Y.K. and F.W.; methodology, F.W.; project administration, F.W.; resources, Y.K. and F.W.; software, Y.K.; supervision, F.W.; validation, F.W.; writing - original draft, Y.K. and F.W.; writing - review and editing, F.W. All authors have read and agreed to the published version of the manuscript.

Funding: This work was partially supported by the Fundamental Research Funds for the Central Universities (Grant JUSRP51735B).

Conflicts of Interest: The authors declare no conflict of interest.

\section{References}

1. International Organization for Standardization. Moderate Thermal Environments-Determination of the PMV and PPD Indices and Specification of the Conditions for Thermal Comfort; International Organization for Standardization: Geneva, Switzerland, 2005. 
2. International Organization for Standardization. Ergonomics of the Thermal Environment-Analytical Determination and Interpretation of Heat Stress Using Calculation of the Predicted Heat Strain; International Organization for Standardization: Geneva, Switzerland, 2004.

3. Havenith, G.; Heus, R.; Lotens, W.A. Resultant clothing insulation: A function of body movement, posture, wind, clothing fit and ensemble thickness. Ergonomics 1990, 33, 67-84. [CrossRef]

4. Kurazumi, Y.; Tsuchikawa, T.; Yamato, Y.; Sakoi, T.; Bolashikov, Z.D.; Kndo, E.; Fukagawa, K.; Tobita, K.; Matsubara, N.; Horikoshi, T. Measurement of heat transfer coefficients of leg-out sitting and chair sitting human body under forced convection from front and back. J. Hum. Living Environ. 2013, 20, 51-61.

5. Li, J.; Guo, X.; Wang, Y. Temperature rating prediction of Tibetan robe ensemble based on different wearing ways. Appl. Ergon. 2012, 43, 909-915. [CrossRef]

6. Luo, N.; Weng, W.; Fu, M.; Yang, J.; Han, Z. Experimental study of the effects of human movement on the convective heat transfer coefficient. Exp. Therm. Fluid Sci. 2014, 57, 40-56. [CrossRef]

7. Morrissey, M.P.; Rossi, R.M. The effect of wind, body movement and garment adjustments on the effective thermal resistance of clothing with low and high air permeability insulation. Text. Res. J. 2014, 84, 583-592. [CrossRef]

8. Nielsen, R.; Olesen, B.W.; Fanger, P.O. Effect of physical activity and air velocity on the thermal insulation of clothing. Ergonomics 1985, 28, 1617-1631. [CrossRef] [PubMed]

9. Olesen, B.W.; Sliwinska, E.; Madsen, T.L.; Fanger, P.O. Effect of body posture and activity on the thermal insulation of clothing: Measurement by a movable thermal manikin. ASHRAE Trans. 1982, 88, 791-805.

10. Oguro, M.; Arens, E.; de Dear, R.; Zhang, H.; Katayama, T. Evaluation of the effect of air flow on clothing insulation and total heat transfer coefficient for each part of the clothed human body. J. Arch. Plan. Environ. Eng. (AIJ) 2001, 549, 13-21.

11. Vogt, J.J.; Meyer, J.P.; Candas, V.; Libert, L.P.; Sagot, J.C. Pumping effect on thermal insulation of clothing worn by human subjects. Ergonomics 1983, 26, 963-974. [CrossRef]

12. Lu, Y.; Song, G.; Li, J.; Wang, F. The impact of air gap on thermal performance of protective clothing against hot water spray. Text. Res. J. 2015, 85, 709-721. [CrossRef]

13. Sung, S.K. Study on the thermal insulation effect of Korean men's folk clothes. J. Therm. Biol. 1993, 18, 409-412. [CrossRef]

14. Lee, Y.; Hong, K.; Hong, S.A. 3D Quantification of microclimate volume in layered clothing for the prediction of clothing insulation. Appl. Ergon. 2007, 38, 349-355. [CrossRef] [PubMed]

15. Chen, Y.; Fan, J.; Qian, X.; Zhang, W. Effect of garment fit on thermal insulation and evaporative resistance. Text. Res. J. 2004, 74, 742-748. [CrossRef]

16. He, S.; Huang, D.; Qi, Z.; Yang, H.; Hu, Y.; Zhang, H. The effect of air gap thickness on heat transfer in firefighters' protective clothing under conditions of short exposure to heat. Heat Transf. Res. 2011, 43, 749-765. [CrossRef]

17. Kim, I.Y.; Lee, C.; Li, P.; Corner, B.D.; Paquette, S. Investigation of air gaps entrapped in protective clothing systems. Fire Mater. 2002, 26, 121-126. [CrossRef]

18. Song, G. Clothing Air gap layers and thermal resistance performance in single layer garment. J. Ind. Text. 2007, 36, 193-205. [CrossRef]

19. Lu, Y.; Song, G.; Li, J. A novel approach for fit analysis of thermal protective clothing using three-dimensional body scanning. Appl. Ergon. 2014, 45, 1439-1446. [CrossRef]

20. Li, J.; Zhang, Z.; Wang, Y. The relationship between air gap sizes and clothing heat transfer performance. J. Text. Inst. 2013, 104, 1327-1336. [CrossRef]

21. Al-ajmi, F.F.; Loveday, D.L.; Bedwell, K.H.; Havenith, G. Thermal insulation and clothing area factors of typical Arabian gulf clothing ensembles for males and females: Measurements using thermal manikins. Appl. Ergon. 2011, 39, 407-414. [CrossRef]

22. Havenith, G.; Kuklane, K.; Fan, J.; Hodder, S.; Ouzzahra, Y.; Lundgren, K.; Au, Y.; Loveday, D. A database of static clothing thermal insulation and vapor permeability values of non-Western ensembles for use in ASHRAE Standard 55, ISO 7730, and ISO 9920 CH-15-018 (RP-1504). ASHRAE Trans. 2015, 121, 197-215.

23. American Society of Heating, Refrigerating and Air-Conditioning Engineers. Thermal Environmental Conditions for Human Occupancy; American Society of Heating, Refrigerating and Air-Conditioning Engineers: Peachtree Corners, GA, USA, 2013. 
24. International Organization for Standardization. Ergonomics of the Thermal Environment-Estimation of the Thermal Insulation and Evaporative Resistance of a Clothing Ensemble; International Organization for Standardization: Geneva, Switzerland, 2009.

25. Lu, Y.; Wang, F.; Wan, X.; Song, G.; Shi, W.; Zhang, C. Clothing resultant thermal insulation determined on a movable thermal manikin. Part I: Effects of wind and body movement on total resultant insulation. Int. J. Biometeorol. 2015, 59, 1475-1486. [CrossRef] [PubMed]

26. International Organization for Standardization. Clothing-Physiological Effects-Measurement of Thermal Insulation by Means of a Thermal Manikin; International Organization for Standardization: Geneva, Switzerland, 2004.

27. McCullough, E.A.; Jones, B.W.; Huck, J. A comprehensive data base for estimating clothing insulation. ASHRAE Trans. 1985, 91, 29-47.

28. Mecheels, J.H.; Umbach, K.H. The psychrometric range of clothing systems. In Clothing Comfort: Interaction of Thermal, Ventilation, Construction and Assessment Factors; Hollies, N.R.S., Goldman, R.F., Eds.; Ann Arbor Science Publishers: Ann Arbor, CA, USA, 1997; pp. 133-151.

29. Daanen, H.; Hatcher, K.; Havenith, G. Determination of clothing microclimate volume. In Environmental Ergonomics; Tochihara, Y., Ohnaka, T., Eds.; Elsevier Ltd.: Oxford, UK, 2005; pp. 361-365.

30. Psikuta, A.; Frackiewicz-Kaczmarek, J.; Frydrych, I.; Rossi, R. Quantitative evaluation of air gap thickness and contact area between body and garment. Text. Res. J. 2012, 82, 1405-1413. [CrossRef]

(C) 2020 by the authors. Licensee MDPI, Basel, Switzerland. This article is an open access article distributed under the terms and conditions of the Creative Commons Attribution (CC BY) license (http://creativecommons.org/licenses/by/4.0/). 